\title{
Gestão ambiental: uma súplica do planeta, um desafio para políticas públicas, incubadoras e pequenas empresas
}

\author{
Sergio Azevedo Fonseca, ${ }^{\mathrm{a}, *}$, Paulo Sérgio Martins ${ }^{\mathrm{b}}$ \\ a,*saf@fclar.unesp.br, UNESP, Brasil \\ bpsmar5@yahoo.com.br, USP, Brasil
}

\begin{abstract}
Resumo
0 texto traz uma reflexão sobre o papel das incubadoras de empresas no apoio a práticas ambientais por micro e pequenas empresas. Reconhecendo as debilidades estruturais das empresas de pequeno porte e as dificuldades para a realização de investimentos ambientais, defende o uso de incubadoras como instrumento de política pública para estimular investimentos ambientais. Identifica um número restrito de incubadoras de tecnologias ambientais, em plano internacional. Relata os resultados de uma pesquisa que avaliou a aplicabilidade de um indicador para apurar o desempenho ambiental de incubadoras. Destacaram-se dois resultados: a) a baixa importância atribuída, pelas incubadoras (e pelas empresas abrigadas) ao desempenho ambiental; e b) a ausência de estímulos, pelas incubadoras, aos investimentos ambientais. Desse último resultado deriva importante conclusão: a de que, uma vez apurados os padrões insatisfatórios de desempenho ambiental, de incubadoras e empresas assistidas, ficariam criadas as condições para a formulação e a implementação de medidas indutoras de novas posturas.
\end{abstract}

Palavras-chave

Incubadora de empresas. Indicador de estratégia ambiental. Sistema de gestão ambiental. Incubadora de tecnologias ambientais. Avaliação do desempenho ambiental de incubadoras.

\section{Introdução}

As preocupações com a questão ambiental vêm ganhando espaço nas agendas públicas e privadas em todo o planeta. Os padrões predominantes de produção e consumo, aprimorados ao longo de todo o século XX, estão se tornando insustentáveis. Para o enfrentamento dessas tendências, ampliam-se e aprofundam-se as pressões sobre as empresas pela adoção de sistemas de gestão ambiental (KUEHR, 2007).

Se, por um lado, as grandes empresas têm facilidade para a mobilização de recursos, próprios ou de terceiros, para financiar projetos e investimentos capazes de contribuir para a melhoria das condições ambientais - inserindo-as no campo da responsabilidade socioambiental -, por outro, as micro e pequenas empresas se veem, em regra, alijadas dessas possibilidades. Defende-se neste texto que um dos instrumentos institucionais passíveis de serem utilizados para superar esse distanciamento entre as micro e pequenas empresas e a gestão ambiental é justamente o das incubadoras de empresas.

Para refletir sobre essa possibilidade foi testada a aplicabilidade de um indicador de performance, criado com o intuito de avaliar o desempenho das incubadoras e das empresas abrigadas, sob a ótica ambiental. 0 indicador é parte de um modelo de avaliação de desempenho de incubadoras de empresas que vem sendo construído, com o apoio da Fapesp. 0 teste foi realizado em três incubadoras situadas no interior do estado de São Paulo.

0 estudo teve, como principais motivações, a necessidade de contribuir para maior difusão da consciência ambiental junto ao meio empresarial e a constatação da grande escassez de referências, na literatura, sobre esforços, potenciais ou reais, de incubadoras de empresas para o estímulo de práticas ambientais, agregando a dimensão ambiental à perspectiva econômica das empresas abrigadas. 
0 texto está estruturado em nove tópicos, incluindo este. No próximo é resgatado um breve histórico da evolução do movimento ambientalista e da concepção da ideia da sustentabilidade do desenvolvimento. Na seção seguinte é abordada a questão da incorporação da dimensão ambiental pelas empresas, dando destaque aos sistemas de gestão ambiental. 0 quarto tópico enfoca a pequena empresa, notadamente no que diz respeito às suas dificuldades e restrições para a realização de investimentos de caráter ambiental. Na quinta seção são expostos alguns exemplos de incubadoras, presentes na arena internacional, que atuam sob a perspectiva ambiental. 0 sexto tópico apresenta a metodologia utilizada. A sétima seção mostra o indicador de estratégia ambiental proposto pelo trabalho. 0 oitavo tópico discute o teste da aplicabilidade do indicador em três incubadoras, e o último tópico trata dos resultados da pesquisa.

\section{0 advento das preocupações com 0 meio ambiente}

Alicerçado no tripé abundância de recursos naturais (inclusive energéticos), aumento da produtividade do trabalho e presença do Estado de Bem-Estar Social, o padrão de "desenvolvimento" predominante ao longo de praticamente todo o século XX parecia, até os anos 70, solidamente implantado e inabalável. A partir dessa década, os pressupostos que sustentavam os padrões de produção e de consumo começam a sofrer fortes questionamentos. Os primeiros abalos são resultantes do efeito combinado da crise do petróleo com a publicação, pelo Clube de Roma, do relatório "Os limites do crescimento" (BUARQUE, 2004).

Os alertas sobre os riscos, para o planeta, da manutenção do ritmo de exploração dos recursos naturais são enfatizados em 1972 na Conferência das Nações Unidas sobre o Meio Ambiente Humano, realizada em Estocolmo. Considerada um marco fundamental para uma nova compreensão sobre o processo de desenvolvimento e sua relação com o meio ambiente, uma das suas principais contribuições foi a de conceber o desenvolvimento e o meio ambiente como partes de um mesmo processo (BARBIERl, 2006). Essa conferência representou, também, o início da popularização do movimento ambientalista em plano internacional.

Com a missão de reavaliar o meio ambiente no contexto do desenvolvimento, a Assembleia Geral da ONU cria, em 1983, a Comissão Mundial sobre Meio Ambiente e Desenvolvimento (Brundtland Comission). Em 1987 essa comissão publica o relatório Nosso futuro comum, introduzindo o termo "desenvolvimento sustentável", entendido como:

[...] aquele que atende às necessidades do presente sem comprometer a possibilidade das gerações futuras de atenderem as suas próprias necessidades [...] (COMISSÃO MUNDIAL SOBRE MEIO AMBIENTE E DESENVOLVIMENTO, 1991, p. 46).

No Brasil, um fato pontual, e ao mesmo tempo perverso, marca o despertar da popularização da consciência ambiental: o assassinato do seringalista Chico Mendes, em dezembro de 1988.

A década de 1990 experimenta um significativo crescimento de iniciativas e instituições preocupadas com as questões sociais e ambientais do planeta. Em 1992, é realizada, no Rio de Janeiro, a Conferência das Nações Unidas sobre Desenvolvimento e Meio Ambiente (ECO-92), mobilizando os governos, o meio empresarial (pela primeira vez!) e a comunidade científica e ambientalista de todo o mundo. Estava em pauta a discussão de questões relevantes ao meio ambiente e à sociedade. Como principal resultado da conferência, a cúpula de nações aprova a Agenda 21, dando maior disseminação ao conceito de desenvolvimento sustentável.

Acompanhando esse movimento de despertar de consciências, as últimas quatro décadas observam o surgimento de grande número de inovações tecnológicas e organizacionais, que preparam a emergência e a configuração de um novo paradigma de desenvolvimento com respostas diferentes aos problemas e desafios da nova realidade. Criam-se as condições materiais para a emergência de ideias e propostas para um novo padrão de desenvolvimento, concebido em oposição e como alternativa ao economicismo do pensamento neoclássico (BUARQUE, 2004).

\section{A incorporação da dimensão ambiental pelas empresas}

Um dos múltiplos efeitos das crescentes mobilizações, em nível planetário, em prol da valorização das temáticas ambiental e social, no contexto das estratégias de desenvolvimento, foi o surgimento de pressões pela incorporação de preocupações sociais e ambientais pelas empresas.

A variável, ou componente, social, começou a ser incorporada ao universo empresarial no início do século passado, notadamente a partir da experiência de Hawthorn, por Elton Mayo. Surgia ali a chamada escola de relações humanas. Desde então, sustentados e impulsionados pelo movimento sindical cada vez mais combativo, os direitos 
trabalhistas e sociais na empresa ganham espaços crescentes, evidentemente que em oposição aos interesses econômicos e à perspectiva maximizadora de lucros. Nessa disputa, defensores da maior valorização dos direitos sociais recebem o apoio de organismos internacionais (especialmente da ONU) a partir dos anos 60, quando da criação, em 1963, do Instituto de Pesquisas das Nações Unidas para o Desenvolvimento Social. Desde então, os resultados das atividades econômicas empresariais (a riqueza gerada) passam a ser cada vez mais "reconhecidos como um direito inalienável de todos" (BARBIERI, 2006, p. 6): ampliavam-se as pressões para que as empresas passassem a destinar um pouco mais de atenção, e de recursos, para o atendimento às demandas sociais. Os efeitos mais significativos dessas pressões somente se fizeram sentir, no entanto, com o surgimento dos movimentos pela responsabilidade social nos anos 90 .

Como aponta Joel Makower, idealizador e dirigente da principal entidade americana representativa dos dirigentes de empresas praticantes da "responsabilidade social", foi apenas em 1992 que as:

[...] empresas praticantes - ou que se consideravam praticantes - de ideais socialmente responsáveis fundaram sua primeira associação, a Business for Social Responsibility, ou BSR [...] (MAKOWER, 1994, p. 112).

Ainda naquela mesma década, os ditames competitivos da globalização espalharam o conceito e as práticas a ele inerentes pelo restante do planeta, notadamente pela Europa, Ásia e América Latina, assumindo o status de movimento da responsabilidade social (COMPÊND10..., 2008). Tais avanços ficaram restritos, no entanto, ao campo social.

A dimensão ambiental foi, historicamente, a última a ter sua importância reconhecida pelo campo empresarial. Resulta disso que, no plano teórico, os estudos sobre o tema, embora já sejam volumosos, são recentes, não alcançando mais do que uma década e meia. E quando se fala em tema, a referência é a gestão ambiental na empresa.

Esse é, exatamente, um dos referenciais deste estudo. Pretende-se abordar e discutir as possibilidades e potencialidades de adoção da gestão ambiental, mesmo que em termos parciais, pelas pequenas empresas. 0 contexto institucional no qual se insere o estudo é delimitado pelo campo de atuação das incubadoras de empresas. Essa circunscrição tem apoio em dois indicativos: o de que as pequenas empresas possuem restrições estruturais para a realização de investimentos que não diretamente relacionados com a dimensão econômica; o de que as incubadoras podem se constituir em importantes mecanismos facilitadores para a superação, ao menos em parte, daquelas limitações.

\subsection{Investimentos empresariais em sistemas de gestão ambiental}

Nas palavras do professor José Carlos Barbieri, da Escola de Administração de Empresas de São Paulo, Fundação Getulio Vargas, a gestão ambiental corresponde ao conjunto das:

[...] atividades administrativas e operacionais realizadas pela empresa para abordar problemas ambientais decorrentes da sua atuação ou para evitar que eles ocorram no futuro [...] (BARBIERI, 2004, p. 137).

0 mesmo professor Barbieri identifica três formas de abordagem de gestão ambiental. A primeira delas é de controle da poluição, cujas práticas, caracterizadas como reativas, levam apenas ao cumprimento da legislação e ao estabelecimento de ações para impedir os efeitos decorrentes dos rejeitos gerados pelos processos produtivos, as chamadas soluções end-of-pipe. Outro posicionamento, passível de ser classificado como intermediário, é o da prevenção da poluição, em que se conjugam esforços para obter a ecoeficiência da função produção. A última das três posturas, com significado proativo, é definida como abordagem estratégica, na qual a variável ambiental passa a ser componente indissociável da estratégia da empresa. Assim, além de práticas de controle e prevenção da poluição, a organização procura aproveitar as oportunidades mercadológicas e se antecipar aos problemas referentes à questão ambiental.

Outra perspectiva de abordagem evolutiva da gestão ambiental é a sistematizada por Garrod e Chadwick (1996). Para os autores, os estágios para a implantação da gestão ambiental seriam: 1) a inspeção (ou análise) ambiental; 2) a formulação de políticas ambientais; e 3) a auditoria ambiental (ao alcance apenas das grandes empresas). Trata-se de uma abordagem cujos estágios podem ser cruzados com os de Barbieri. Já Perez-Sanchez, Barton e Bower (2003) sugerem uma estratégia para implementação de sistemas de gestão ambiental em pequenas empresas, composta por cinco estágios: 1) obtenção de apoio financeiro; 2) definição de uma estratégia de longo prazo, consubstanciada em um plano bem elaborado; 3) desenvolvimento de competências internas; 4) construção de redes externas; e 5) criação de clima e cultura organizacional favoráveis à inovação. 
Em termos históricos - e aí a referência é à história recente -, a evolução da gestão ambiental acompanhou e foi favorecida pelo aprimoramento, de um lado, da legislação ambiental nos mais diferentes países (algo que não será objeto de abordagem neste texto) e, de outro, das normas de certificação ambiental (JABBOUR, 2007). Nesse último caso cabe dar destaque à norma ISO 14001 e à Ekoscan (HERAS; ARANA, 2010). Ambos são modelos de gestão ambiental, que visam orientar as empresas na elaboração de políticas ambientais e no estabelecimento de estratégias, objetivos e metas, levando em consideração os impactos ambientais e a legislação ambiental em vigor no país (NICOLELLA; MARQUES; SKORUPA, 2004). A adoção dessas medidas implica, evidentemente, na realização de investimentos, não apenas no plano da gestão, mas também em tecnologias de produtos e processos. No caso da $1 S 0$ 14001, são demandados investimentos que, de acordo com Miles, Munilla e McClug (1999), ficam praticamente proibitivos para as micro e pequenas empresas, em virtude dos elevados montantes de recursos que demandam e da escassez de pessoal interno capacitado para desenvolver os processos e sistemas exigidos pelos padrões da norma. Já o modelo Ekoscan, embora concebido (no País Basco) com foco nas pequenas empresas, ainda assim demanda investimentos nem sempre ao alcance das micro e pequenas empresas menos capitalizadas.

Não bastam, no entanto, os investimentos na infraestrutura e na implantação das medidas previstas nas normas: há que se investir, também, no fortalecimento da consciência ambiental internamente às empresas. E essa é outra frente de investimentos que demanda um aporte nada desprezível de recursos. Algo muito mais ao alcance das grandes empresas: pressupõe grande mobilização de esforços para realizar as necessárias e profundas mudanças na cultura organizacional.

A restrição, que mais uma vez deve ser apontada, é que esse padrão de investimentos, do mesmo modo que as correspondentes linhas de financiamento, é acessivel quase exclusivamente às médias e grandes empresas. Pesquisa realizada em 2003 pela Federação das Indústrias do Estado de São Paulo (FEDERAÇÃO..., 2003), para coletar dados a respeito da atuação das empresas no campo da responsabilidade socioambiental, corrobora essa constatação ao apontar que, embora o número de pequenas empresas constantes da amostra fosse substantivamente superior ao de médias e grandes, as ações, e os consequentes investimentos, nos campos da "responsabilidade social e ambiental" estiveram praticamente concentradas nos dois últimos grupos.

\section{A pequena empresa e suas restrições para a realização de investimentos ambientais}

A escolha preferencial pela abordagem, na pesquisa, do campo das Micro e Pequenas Empresas - MPEs - decorre da consciência da sua importância nos contextos econômico, social e ambiental. Segundo dados do Sebrae (2006), as MPEs representavam, em 2005, 98\% do total de 5,1 milhões de empresas brasileiras, empregando $67 \%$ do pessoal ocupado no setor privado, sendo responsáveis por $43 \%$ da renda gerada nos setores industrial, comercial e de serviços, montante esse correspondente a 20\% do PIB brasileiro. Sob a ótica dos investimentos nos campos social e ambiental, os dados já não são tão promissores: tomando-se o número de MPEs associadas ao Instituto ETHOS, composto por 249 microempresas e 365 pequenas empresas, chega-se à ínfima proporção de 0,00012\% em relação ao total de empresas formais existentes no país, de acordo com o IBGE; esse perfil é confirmado, de maneira ainda mais explícita, pela outra organização representativa do movimento brasileiro pela responsabilidade socioambiental, o Conselho Empresarial Brasileiro para o Desenvolvimento Sustentável - CEBDS, que, em sua página na Internet", declara que a entidade "representa grandes grupos empresariais" (CONSELHO..., 2008). Em âmbito internacional, essa mesma realidade - da importância econômica e social da pequena empresa e do seu distanciamento em relação à gestão ambiental - se replica, como mostram Rutherfoord, Blackburn e Spence (2000), Brio e Junquera (2003) e Redmond, Walker e Wang (2008).

Como se procurou sustentar na seção anterior do texto, o trânsito das MPEs em direção à adoção da consciência e à incorporação de práticas ambientais demanda volumes expressivos de investimentos. É condição imprescindível a geração e a difusão de inovações em tecnologias de produtos, processos e sistemas de gestão. Além disso, são necessários investimentos na capacitação (novos padrões de conhecimento) e no treinamento de pessoas.

A premência da incorporação, pelas micro e pequenas empresas, de medidas que contribuam para a melhoria do seu desempenho ambiental evidencia-se, ainda mais, em virtude do fato de elas serem responsáveis por elevada proporção dos danos causados ao meio ambiente em decorrência da atividade empresarial - mais de 70\% no Reino Unido, de acordo com Perez-Sanchez, Barton e Bower (2003).

\footnotetext{
* (http://www.cebds.org.br/cebds/cebds-associados.asp)
} 
A realização de tais investimentos pelas micro e pequenas empresas fica, no entanto, condicionada e limitada por um conjunto de fatores que podem ser qualificados como componentes culturais e debilidades estruturais desse segmento empresarial.

Entre os principais componentes culturais (próprios do ambiente empresarial, evidentemente), destacariam-se a aversão ao risco inerente a investimentos com perspectivas incertas de resultado e o foco na performance econômicofinanceira da empresa como elementos centrais das estratégias da grande maioria das micro e pequenas empresas de recorte mais tradicional (GARROD; CHADWICK, 1996).

Já as debilidades estruturais foram sistematizadas por Fonseca (2000), com base em estudos de pelo menos dez autores, com destaque para as seguintes: baixa intensidade de capital - atividades usualmente intensivas em trabalho; capacidade de financiamento restrita - baixo acesso ao crédito; precariedade da função gerencial; baixa qualificação da força de trabalho; precariedade da função tecnológica; falta de planejamento a longo prazo. 0 autor, do mesmo modo que Perez-Sanchez, Barton e Bower (2003), aponta que esses são fatores gerais, que afetam e comprometem as estratégias genéricas das micro e pequenas empresas.

Corroborando as mesmas constatações, porém com foco no desempenho ambiental, Brio e Junqueira (2003) sustentam que as estratégias ambientais das micro e pequenas, quando existentes, apresentam baixo desenvolvimento, são meramente reativas e que o componente ambiental não se constitui em diretriz para mudanças estratégicas. Na visão dos autores, convergente com a de Fonseca (2000), essas dificuldades, do mesmo modo que a propensão dessas empresas para incorporar inovações ambientais, seriam resultantes de combinações entre fatores como: escassez de recursos financeiros, tipo da estrutura organizacional, baixa capacitação ambiental de gestores e trabalhadores, visão de curto prazo, escassez de competências técnicas para incorporar inovações, entre outros.

De forma complementar, Merritt (1998) e Jeppesen (2005) apontam que a promoção da gestão ambiental nas micro e pequenas empresas somente pode ser exitosa se acompanhada de uma profunda compreensão da natureza bastante heterogênea das micro e pequenas empresas e dos contextos socioeconômicos extremamente diversificados em que elas operam.

Esse conjunto de restrições e dificuldades possui um forte componente estrutural, repousado sobre fatores históricos, culturais, econômicos, políticos e sociais. Isso implica dizer que a superação desses componentes pressupõe a conjugação de um vasto leque de iniciativas e medidas, passíveis de serem abrigadas sob o manto de instrumentos e mecanismos de políticas públicas de apoio ao desenvolvimento de micro e pequenas empresas. Um desses instrumentos, que vem se mostrando exitoso há mais de duas décadas no apoio ao desenvolvimento de micro e pequenas empresas sob a ótica econômica, é o correspondente às incubadoras de empresas.

Uma sugestão, passível de ser confirmada, é a de que, alcançando resultados favoráveis na agregação de sistemas de gestão ambiental às empresas incubadas, as incubadoras podem contribuir para um fortalecimento ainda maior das empresas. lsso porque, como reconhece Jeppesen $(2005$, p. 3), a implementação de tais sistemas conduz a "situações de ganha-ganha”: as empresas saem ganhando em suas atividades de negócios e o público interno e externo se beneficia com os avanços nos campos social e ambiental.

Para confirmar as suspeitas até aqui levantadas e verificar a plausibilidade das ideias propostas, foi realizado um levantamento dos perfis de incubadoras existentes, com declaradas estratégias ambientais, e efetuado um teste da consistência das variáveis de um indicador de desempenho ambiental de incubadoras genéricas - de qualquer tipo.

\section{Notas metodológicas}

A estratégia metodológica utilizada para a coleta e a análise dos dados empíricos que deram suporte para a realização deste estudo articulou múltiplos instrumentos, concebidos e aplicados em conformidade com as premissas do método qualitativo, com um propósito essencialmente exploratório. 0 levantamento dos dados relativos às incubadoras de tecnologias ambientais, cujos resultados são apresentados na seção 6 , foi realizado por meio de técnicas aplicáveis à análise documental, tendo como objetos documentos eletrônicos contidos em páginas da Internet. Já os dados de campo, coletados junto a três incubadoras com a finalidade de testar a aplicabilidade das variáveis sugeridas e a validade do indicador proposto, foram coletados por meio de entrevistas e da observação direta. As análises dos dados, em ambos os casos, foram realizados por meio de cruzamentos. Os detalhamentos metodológicos antecedem as respectivas exposições dos dados. 


\section{Incubadoras ambientais}

As suspeitas dos autores deste texto quanto à escassez de referências na literatura sobre estudos relativos a incubadoras com enfoque ambiental se confirmaram ao longo da pesquisa. A estratégia metodológica utilizada nesse estágio da pesquisa percorreu os campos da pesquisa bibliográfica e da pesquisa documental. 0 primeiro delineamento, para buscar textos já publicados, sobretudo em periódicos. As bases consultadas foram as disponíveis em portais da Internet, notadamente na Web of Science e no Scielo. 0 segundo delineamento é aplicável, de acordo com Gil (1991), nos casos em que os materiais consultados ainda não receberam tratamento analítico. Enquadraram-se nesse procedimento metodológico os levantamentos realizados, essencialmente em páginas da Internet. Para a realização das buscas, tanto na pesquisa bibliográfica como na documental, foi utilizado um grande número de combinações de palavras-chave, em três idiomas: inglês, português e castelhano. Reconhece-se que o levantamento realizado, embora tenha sido exaustivo, consumindo mais de 40 horas de buscas, não pode ser considerado completo, em virtude das seguintes restrições: da possivel omissão, involuntária, de chaves de busca; da eventual existência de outras incubadoras, sem registro em páginas da Internet; da limitação imposta pelos idiomas de busca.

0 que a pesquisa realizada revelou foi a existência, em âmbito planetário, de um número supostamente ainda muito restrito de programas, modalidades ou iniciativas de incubadoras com marcas ambientais. Essa timidez quantitativa é evidenciada quando se confrontam os números levantados com os totais estimados de incubadoras de todos os tipos que, de acordo com dados da National Business Incubation Association - entidade norte-americana que congrega as incubadoras daquele país - ultrapassavam, em 2008, a casa das quatro mil em todo o planeta (NATIONAL..., 2008). Ora, diante desse registro fica confirmado o patamar nitidamente incipiente dessa modalidade de incubadora. Os dados resultantes do levantamento constam do Quadro 1.

Uma primeira constatação, talvez a principal, que pode ser extraída do quadro é a relativa ao perfil das incubadoras. Observa-se que a totalidade delas tem, como estratégia, a oferta de apoios, de variados tipos, a empresas, ou empreendedores, cujos negócios estão voltados para o desenvolvimento de tecnologias ambientais - notadamente de produtos, serviços e processos. Essa constatação deve implicar o reconhecimento de que são incubadoras que atuam junto a empreendimentos e projetos situados em fronteiras tecnológicas. Algo que possa ser associado à escala mais elevada das três abordagens sugeridas pelo prof. Barbieri. A fim de delimitar conceitualmente esse campo, sugere-se a denominação de Incubadoras de Tecnologias Ambientais à tipologia das unidades constantes do quadro.

A segunda constatação é a de que ficam explicitamente excluídas, desse padrão de estratégia de incubadoras, as medidas, ações e práticas enquadráveis nas duas primeiras abordagens de Barbieri. Isso significa o reconhecimento de que um vasto leque de iniciativas passíveis de contribuírem para aprimorar o desempenho ambiental de empresas genéricas - que representam a esmagadora maioria do universo das micro e pequenas empresas - não estão presentes entre os tipos de atividades oferecidas pelas incubadoras de tecnologias ambientais.

Essa constatação, aliada à já revelada iminente necessidade da criação de mecanismos que apoiem o aprimoramento do desempenho ambiental das micro e pequenas empresas, reforça a ideia de conceber instrumentos, passíveis de serem incorporados por incubadoras de qualquer modalidade, capazes de gerar efeitos ambientais positivos às empresas assistidas, às incubadoras e ao ambiente externo.

É nesse plano que se enquadra a proposta detalhada na seção 7 deste texto. As medidas descritas, denominadas variáveis de um indicador, compõem um modelo mais amplo, idealizado para avaliar o desempenho de incubadoras (JABBOUR; FONSECA, 2005).

\section{Indicador de estratégia ambiental}

0 indicador de estratégia ambiental tem o propósito de apurar o grau de comprometimento das incubadoras com a dimensão ambiental das suas atividades e das empresas abrigadas. As variáveis devem ser passíveis de aplicação a qualquer tipo de incubadora e a qualquer atividade econômica das empresas incubadas.

Em termos metodológicos, o quadro foi elaborado com base nos componentes do sistema de gestão ambiental defendido por Barbieri (2004), acompanhados por aspectos da norma 150 14001 e por resultados de observações empíricas realizadas quando de visitas do autor e de sua equipe de pesquisadores a um número superior a dez incubadoras no estado de São Paulo. 0 Quadro 2 retrata o indicador, os subindicadores e as variáveis. 
Quadro 1. Programas e incubadoras com enfoque ambiental.

\begin{tabular}{|c|c|c|c|}
\hline $\begin{array}{c}\text { Nome } \\
\text { (data de criação) }\end{array}$ & $\begin{array}{c}\text { Natureza e vínculo } \\
\text { institucional }\end{array}$ & Estratégia de apoio & Abrangência \\
\hline $\begin{array}{l}\text { Environmental } \\
\text { Technology Incubator } \\
\text { Program (2003)' }\end{array}$ & $\begin{array}{l}\text { Projeto de responsabilidade } \\
\text { da Agência de Proteção } \\
\text { Ambiental de Taiwan. }\end{array}$ & $\begin{array}{l}\text { Agência concede apoio financeiro } \\
\text { a incubadoras e empresas para o } \\
\text { desenvolvimento de tecnologias ou } \\
\text { equipamentos ambientais. }\end{array}$ & $\begin{array}{c}\text { Empresas que desenvolvem tecnologias de } \\
\text { tratamento de resíduos, de recuperação, } \\
\text { reciclagem e reuso de resíduos e recursos } \\
\text { e de análise ambiental. }\end{array}$ \\
\hline $\begin{array}{l}\text { The Alliance of Clean } \\
\text { Energy Business } \\
\text { Incubators }(2000)^{2}\end{array}$ & $\begin{array}{c}\text { Rede de incubadoras } \\
\text { vinculada ao NREL (EUA). }\end{array}$ & $\begin{array}{l}\text { Laboratório apoia incubadoras por meio } \\
\text { de rede de investidores, especialistas em } \\
\text { energia e potenciais clientes. }\end{array}$ & $\begin{array}{l}\text { Empresas que desenvolvem tecnologias } \\
\text { de energias limpas. }\end{array}$ \\
\hline $\begin{array}{l}\text { Sweden Cleantech } \\
\text { Incubators }(2007)^{3}\end{array}$ & $\begin{array}{l}\text { Incubadora Virtual, } \\
\text { vinculada à empresa } \\
\text { sueca Teknopol AB. }\end{array}$ & $\begin{array}{l}\text { Apoia incubadoras na agregação de } \\
\text { tecnologias limpas a negócios nascentes. }\end{array}$ & $\begin{array}{c}\text { Empresas de variados setores de atividade } \\
\text { ambientalmente sustentáveis. }\end{array}$ \\
\hline $\begin{array}{l}\text { NUS Cleantech } \\
\text { Incubator }(2002)^{4}\end{array}$ & $\begin{array}{c}\text { Incubadora vinculada à } \\
\text { Universidade Nacional } \\
\text { de Singapura. }\end{array}$ & $\begin{array}{l}\text { Incubadora oferece apoio, instalações e } \\
\text { recursos de financiamento para inventores } \\
\text { e empreendedores. }\end{array}$ & $\begin{array}{l}\text { Empreendimentos com menos de três } \\
\text { anos, que desenvolvem tecnologias } \\
\text { ambientais. }\end{array}$ \\
\hline $\begin{array}{l}\text { Sustainable Business } \\
\text { Incubator }(2007)^{5}\end{array}$ & $\begin{array}{l}\text { Programa do Instituto para } \\
\text { a Empresa Sustentável, } \\
\text { da Universidade Fairleigh } \\
\text { Dickinson, EUA. }\end{array}$ & $\begin{array}{l}\text { Incubadora virtual, que oferece apoio a } \\
\text { negócios com tecnologias verdes, que } \\
\text { projetem práticas sustentáveis de negócios } \\
\text { ou invistam em novos negócios ambientais. }\end{array}$ & $\begin{array}{l}\text { Empresas que atuam nos campos de } \\
\text { energias e combustíveis alternativos, } \\
\text { conservação e reuso de água, de sequestro } \\
\text { de carbono, de hidroponia, entre outros. }\end{array}$ \\
\hline $\begin{array}{l}\text { Claude Laval WET } \\
\text { Incubator }(2007)^{6}\end{array}$ & $\begin{array}{l}\text { Incubadora vinculada à } \\
\text { Universidade do Estado da } \\
\text { Califórnia, EUA. }\end{array}$ & $\begin{array}{l}\text { Centro de atividades para } \\
\text { empreendedores, oferecendo acesso à } \\
\text { indústria, a especialistas e laboratórios. }\end{array}$ & $\begin{array}{l}\text { Empresas que desenvolvem tecnologias } \\
\text { nos campos da água e da energia. }\end{array}$ \\
\hline Incubalix $(2007)^{7}$ & $\begin{array}{l}\text { Incubadora vinculada } \\
\text { ao IMADESA, em } \\
\text { Vitória - ES, BR. }\end{array}$ & $\begin{array}{l}\text { Incubadora apoia empresas, que busquem } \\
\text { alternativas e métodos racionais de uso } \\
\text { dos recursos naturais. }\end{array}$ & $\begin{array}{l}\text { Empresas que desenvolvem tecnologias } \\
\text { para a reciclagem de resíduos para a } \\
\text { produção de bens e serviços. }\end{array}$ \\
\hline
\end{tabular}

'Environmental Technology Incubator Program. Disponivel em: <http://www.epa.gov.tw/en/epashow.aspx?list=122\&path=10337\&guid=86cbca31-aaaa-496c-b8cdef82d0edf7cf\&lang=en-us>. Acesso em: 23 jan. 2009.; ${ }^{2}$ The Nacional Alliance of Clean Energy Business Incubators. Disponivel em: <http://www.cleanenergyalliance. com/ - 6k ->. Acesso em: 23 jan. 2009.; ${ }^{3}$ Sweden Cleantech Incubators. Disponivel em http://www.scti.se/ - 6k - Acesso em: 19 jan. $2009 . ;{ }^{4}$ NUS Cleantech Incubator. Disponivel em: <http://nus.edu.sg/nec/vs/index.html>. Acesso em: 19 jan. 2009.; ${ }^{5}$ Sustainable Business Incubator. Disponivel em: http://view.fdu.edu/default. aspx?id=5209>. Acesso em: 19 jan. 2009.; ${ }^{6}$ Claude Laval WET Incubator. Disponivel em: <http://www.cvbi.org/wet_incubator.htm>. Acesso em: 23 jan. $2009 . ;$ e 7 Incubalix Disponivel em: <http://www.marcaambiental.com.br/incubalix.asp>. Acesso em: 18 jan. 2009.

\subsection{Detalhamento das variáveis}

A primeira variável refere-se às iniciativas que devem estar presentes quando da concepção do projeto da incubadora. 0 projeto, arquitetônico e de engenharia da incubadora, deve propiciar os seguintes efeitos: conforto ambiental com o menor consumo de energia, preferencialmente de fontes renováveis - notadamente solar e eólica; uso de sistemas de captação, tratamento e economia de recursos hídricos, privilegiando, na captação, a origem pluvial; possibilidade de reciclar internamente a maior variedade e o maior volume possível de resíduos gerados pelas operações. Além do projeto das instalações físicas, a gestão das operações internas à incubadora deve ser feita de modo a lhe assegurar o máximo de benefícios ambientais. Os autores sugerem ser esse um perfil de espaço físico próximo do ideal, dificilmente atingivel na realidade da esmagadora maioria, senão a totalidade, das incubadoras brasileiras e, quiçá, em plano internacional.

A segunda variável capta efeitos presentes quando da seleção dos candidatos às incubadoras. Logicamente que, para que tais medidas possam produzir os efeitos auspiciados, é necessária a presença de um conjunto de decisões estratégicas, das instituições mantenedoras, dos conselhos e das direções das incubadoras: pressupõe uma firme determinação para selecionar apenas projetos de empresas que já possuam algum tipo de enfoque ambiental ou que, minimamente, revelem potencial e disposição para implementar medidas de caráter ambiental; demanda a elaboração de roteiros de planos de negócios nos quais estejam explicitadas as condições ambientais para ingresso e permanência; implica a elaboração de editais de seleção que contenham, claramente contemplados, os requisitos ambientais para a aprovação dos projetos; contempla a elaboração de contratos de adesão que apontem, de forma clara, os direitos e as obrigações de cunho ambiental, do mesmo modo que as implícitas punições por descumprimento.

A terceira variável visa medir as ações de caráter permanente que as incubadoras devem realizar, com vistas a assegurar o aprimoramento contínuo das condições e dos efeitos ambientais das operações das empresas - e das suas próprias. São os cursos, treinamentos, visitas, projetos, intercâmbios de informações e outras atividades, tendo o propósito de difundir informações, tecnologias e técnicas ambientais para empresários, trabalhadores e público externo. 
Quadro 2. 0 indicador e suas variáveis.

\begin{tabular}{|c|c|c|}
\hline Indicador & Subindicadores & Variáveis \\
\hline \multirow{3}{*}{ 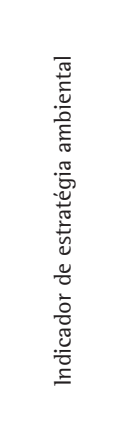 } & Gestão ambiental & $\begin{array}{l}\text { 1. Requisitos ambientais no projeto de infraestrutura da incubadora. } \\
\text { 2. Condicionamento (através do plano de negócios e edital) a cumprimento de requisitos ambientais } \\
\text { pelas empresas. } \\
\text { 3. Atividades permanentes de educação ambiental e de difusão de informações, tecnologias e técnicas } \\
\text { ambientais para empresários, trabalhadores e público externo. }\end{array}$ \\
\hline & $\begin{array}{c}\text { Processos operacionais } \\
\text { da incubadora }\end{array}$ & $\begin{array}{l}\text { 4. Uso de fontes limpas de energia pela incubadora. } \\
\text { 5. Tratamento de esgoto feito pela incubadora. }\end{array}$ \\
\hline & $\begin{array}{l}\text { Processos operacionais } \\
\text { das empresas }\end{array}$ & $\begin{array}{l}\text { 6. Minimização do uso de água no processo produtivo. } \\
\text { 7. Minimização do uso de energia no processo produtivo. } \\
\text { 8. Minimização do uso de insumos do processo produtivo. } \\
\text { 9. Minimização da quantidade dos efluentes (sólidos e líquidos). } \\
\text { 10. Utilização de insumos reciclados ou biodegradáveis. } \\
\text { 11. Reaproveitamento dos descartes. } \\
\text { 12. Diminuição da emissão de gases poluentes. }\end{array}$ \\
\hline
\end{tabular}

A quarta variável avalia a matriz energética das incubadoras, valorizando o uso de fontes limpas de energia (no limite a eólica e a solar). A quinta variável, também considerando, no limite, uma situação ideal, tem o propósito de investigar a existência, o alcance e a qualidade de eventuais sistemas internos de captação, tratamento e disposição de efluentes líquidos.

As variáveis numeradas de 6 a 8 buscam apurar se as empresas investem na redução dos insumos considerados críticos do ponto de vista ambiental: energia, água e matérias-primas. As variáveis 10 e 11 procuram avaliar a presença e a intensidade de duas outras práticas ambientais com uso crescentemente difundido: a substituição de insumos poluentes, não renováveis ou primários, por biodegradáveis, renováveis e reciclados; o reaproveitamento de resíduos e efluentes, tanto no próprio processo produtivo como destinando-os para outras atividades externas.

As variáveis 9 e 12 visam apurar a presença de práticas estreitamente relacionadas com as medidas pela variável 11 , ou seja, a redução do descarte de resíduos e efluentes. Tais práticas significariam, no limite, a eliminação de quaisquer agressões ambientais por poluição.

\section{Resultados}

Para avaliar a validade e a aplicabilidade das variáveis, foi realizada uma pesquisa junto a três incubadoras situadas em igual número de municípios no interior do Estado de São Paulo. A primeira delas com perfil mais próximo da tipologia de tecnológicas e as outras duas situadas no campo das ditas tradicionais. A intencionalidade foi o critério central para a seleção das incubadoras: municípios próximos do campus, para redução de custos; incubadoras com as quais havia certo grau de afinidade com os gerentes, para facilitar a coleta de dados; representatividade tipológica - maior número de tradicionais, menor de tecnológicas. Cumpre observar que esses critérios guardam perfeita afinidade com o delineamento do estudo de casos, como mostra Yin (1990).

Para verificar a aplicabilidade de cada variável às realidades das incubadoras e das empresas incubadas foi necessário investigar as atividades nucleares de cada empresa e conhecer seus processos operacionais.

A estratégia metodológica seguida foi a da pesquisa qualitativa, realizada por meio de visitas às três incubadoras, durante as quais foram coletados dados em profundidade sobre as estruturas físicas e os fluxos e processos das incubadoras e das empresas. 0 delineamento foi o de estudo de casos múltiplos, no qual cada incubadora foi tratada como um caso. Os instrumentos de coleta de dados utilizados foram a observação direta e as entrevistas, ambas apoiadas em roteiros previamente elaborados. A pesquisa revestiu-se de caráter exploratório, inerente à abrangência restrita dos seus resultados - impossibilidade de extrapolação - e ao estágio incipiente do conhecimento no campo particular da gestão ambiental em incubadoras. Os dados foram sendo analisados simultaneamente ao processo de coleta - em conformidade com o método qualitativo - e por cruzamento, para identificar similaridades e distanciamentos. Uma das expectativas presentes é a de que os resultados possam oferecer referenciais metodológicos para uma ampliação do alcance da pesquisa.

0 Quadro 3 apresenta a síntese da análise dos dados.

Conquanto o delineamento da pesquisa tenha sido o do estudo de casos múltiplos, ficará omitida, na análise dos resultados, a descrição detalhada de cada uma das incubadoras que foram objeto do 
estudo: em primeiro lugar, por não estar a descrição entre os objetivos da pesquisa; em segundo, pelo demasiado espaço que ocuparia no texto.

Uma vez concluída a análise dos dados, os textos resultantes foram submetidos aos gerentes das incubadoras, para validação dos resultados, coleta de sugestões e incorporação de ajustes.

A incubadora A, caracterizada como tecnológica, abriga um total de vinte empresas, atuando em ramos de atividades como informática, eletrônica e prestadoras de serviços (nas áreas de comunicação, segurança, agrimensura, ensino a distancia e tecnologia da informação). A incubadora B possui quinze empresas incubadas, treze do ramo industrial e duas prestadoras de serviços. As industriais se dividem em usinagem, produção de chapas de PVC, produção de máquinas de suco e confecções de roupas. Na incubadora C estão abrigadas dez empresas, divididas entre os setores de calçados femininos e de confecções de roupas.

Os resultados registrados como nulos significam a anulação da variável enquanto instrumento de avaliação do respectivo aspecto particular de desempenho ambiental. Em outras palavras, nos casos em que as variáveis se tornam nulas, os aspectos que deveriam ser avaliados não se encontravam presentes. Exemplos típicos dessas situações de anulação são os casos da inexistência de emissão de efluentes por empresas prestadoras de serviços.
Do ponto de vista do teste das variáveis, é possível inferir que as mesmas se mostraram adequadas para apurar a relativa neutralidade ambiental das atividades das empresas investigadas. Ao menos no que diz respeito aos seus processos operacionais. 0 que não foi possível detectar, e aí a falha está na ausência de instrumentos - ou seja, de variáveis -, foram os potenciais efeitos ambientais, à jusante das respectivas cadeias, dos produtos ou serviços ofertados pelas empresas.

No que diz respeito à leitura dos resultados do teste realizado, para cada uma das variáveis foi possível extrair as seguintes constatações:

- As variáveis numeradas de 1 a 4 , aplicáveis para avaliar o desempenho de incubadoras genéricas, enquanto unidades organizacionais, permitiram captar, unicamente, a existência e a presença (ou não) de estratégias, políticas, medidas ou iniciativas relacionadas ao campo ambiental. Não foi possível apurar a amplitude, a intensidade ou a profundidade do desempenho.

- As demais variáveis também se mostraram apenas parcialmente adequadas para a captação do alcance do desempenho ambiental das incubadoras: ofereceram indícios satisfatórios da existência (ou não) de práticas das empresas, passíveis de serem caracterizadas como de cunho ambiental. 0 que mais chamou atenção, no entanto, foi o fato de que não forneceram elementos para identificar até que ponto as raras iniciativas de caráter ambiental

Quadro 3. Resultados da aplicação do indicador ambiental nas incubadoras.

\begin{tabular}{|c|c|c|c|}
\hline Variáveis & lncubadora A & Incubadora B & Incubadora C \\
\hline $\begin{array}{l}\text { 1. Requisitos ambientais no projeto de } \\
\text { infraestrutura da incubadora }\end{array}$ & Inexistente & Inexistente & Inexistente \\
\hline $\begin{array}{l}\text { 2. Condicionamento (através do plano de } \\
\text { negócios e edital) a cumprimento de } \\
\text { requisitos ambientais pelas empresas }\end{array}$ & Não ser poluente & $\begin{array}{l}\text { Proibição da geração } \\
\text { de resíduos }\end{array}$ & Não ser poluente \\
\hline $\begin{array}{l}\text { 3. Atividades permanentes de educação } \\
\text { ambiental e de difusão de informações, } \\
\text { tecnologias e técnicas ambientais para } \\
\text { empresários, trabalhadores e público externo }\end{array}$ & $\begin{array}{c}\text { Promove educação e } \\
\text { difunde técnicas ambientais } \\
\text { para empresários e público } \\
\text { externo }\end{array}$ & $\begin{array}{l}\text { Práticas de educação } \\
\text { ambiental aos empresários }\end{array}$ & Inexistente \\
\hline $\begin{array}{l}\text { 4. Uso de fontes limpas de energia pela } \\
\text { incubadora }\end{array}$ & Inexistente & Inexistente & Inexistente \\
\hline $\begin{array}{l}\text { 5. Sistemas de manejo de efluentes líquidos } \\
\text { pela incubadora }\end{array}$ & Nulo & Nulo & Nulo \\
\hline 6. Redução do uso de água pelas empresas & Nulo & Nulo & Nulo \\
\hline 7. Redução do uso de energia pelas empresas & Nulo & $\begin{array}{l}100 \% \text { das empresas buscam } \\
\text { reduzir o uso de energia }\end{array}$ & $\begin{array}{l}100 \% \text { das empresas buscam } \\
\text { reduzir o uso de energia }\end{array}$ \\
\hline 8. Redução do uso de insumos pelas empresas & Nulo & $\begin{array}{l}\text { 100\% das empresas buscam } \\
\text { reduzir o uso de insumos }\end{array}$ & $\begin{array}{l}100 \% \text { das empresas buscam } \\
\text { reduzir o uso de insumos }\end{array}$ \\
\hline $\begin{array}{l}\text { 9. Redução da emissão de efluentes (sólidos e } \\
\text { líquidos) }\end{array}$ & Nulo & Nulo & Nulo \\
\hline $\begin{array}{l}\text { 10. Utilização de insumos reciclados ou } \\
\text { biodegradáveis }\end{array}$ & Nulo & Inexistente & $\begin{array}{l}\text { 10\% das empresas utilizam } \\
\text { insumos reciclados }\end{array}$ \\
\hline 11. Reaproveitamento dos descartes & Nulo & $\begin{array}{l}100 \% \text { das empresas } \\
\text { reaproveitam os descartes }\end{array}$ & $\begin{array}{l}100 \% \text { das empresas } \\
\text { reaproveitam os descartes }\end{array}$ \\
\hline 12. Redução da emissão de gases & Nulo & Nulo & Nulo \\
\hline
\end{tabular}


detectadas nas empresas - redução do uso de energia e de insumos e reaproveitamento de descartes ocorrem por motivações de caráter ambiental ou por outras razões, e se são implementadas de modo próprio, pelas empresas, ou se por indução das incubadoras. Outra falha detectada foi a ausência de medidas: o formato dos instrumentos não permitiu apurar o grau de comprometimento das empresas com práticas ambientais.

- Para além do propósito de testar as variáveis, os dados coletados forneceram uma evidência preocupante: a ausência, quase completa, de estratégias ambientais explícitas, pelas incubadoras ou pelas empresas abrigadas. Essa constatação deve ser tomada com as devidas reservas, em virtude do alcance limitado e do caráter exploratório da pesquisa.

- Relacionando os resultados com os referenciais de gestão ambiental constantes da literatura, é possivel inferir que tanto as incubadoras como as empresas nelas abrigadas encontram-se, quando muito, enquadráveis no primeiro estágio da classificação de Barbieri (2004). No contexto da abordagem sugerida por Garrod e Chadwick (1996), as incubadoras e as empresas situaram-se aquém do primeiro estágio (de diagnóstico ou inspeção ambiental). 0 mesmo enquadramento se aplica quando referenciado à estratégia sugerida por Perez-Sanchez, Barton e Bower (2003). Quando os modelos referenciais de gestão ambiental são a série ISO 14001 e a Ekoscan, o distanciamento se revela ainda maior.

\section{Conclusões}

Os resultados da pesquisa convergiram com parcela substancial das constatações contidas na literatura, notadamente no que diz respeito à baixa propensão das micro e pequenas empresas para realizarem investimentos ambientais. Quando investem, reagem muito mais a estímulos de ordem econômica do que movidas por educação ambiental ou consciência quanto à necessidade de adotar posturas ambientalmente solidárias.

0 mesmo pode se dizer em relação às incubadoras. Os responsáveis pelas três unidades investigadas durante a pesquisa revelaram, explicitamente, que não é papel da incubadora investir na promoção de estratégias ambientais junto às empresas, ou mesmo na difusão de sistemas de gestão ambiental. Uma inferência que pode ser extraída, e para a qual a pesquisa forneceu indícios, é que os gestores de incubadoras não estão tecnicamente qualificados, e culturalmente convencidos, para enfrentar os desafios inerentes à implantação da gestão ambiental.
É nesse contexto que o instrumental metodológico testado na pesquisa pode se enquadrar. As variáveis, que ora foram utilizadas para avaliar patamares de desempenho de incubadoras, sob a ótica ambiental, podem vir a ser tratadas como instrumentos de apoio, tanto à qualificação dos gestores de incubadoras como ao delineamento das estruturas e fluxos de atividades capazes de inserir as incubadoras no campo da sustentabilidade ambiental.

Para o alcance dessa finalidade é necessário, no entanto, o aprimoramento das variáveis, de modo que possam captar diferentes intensidades dos múltiplos aspectos do desempenho ambiental das incubadoras.

Num plano mais geral, a pesquisa revelou, e aí de forma bastante convergente com a literatura, que diferentes tipos de empresas demandam variadas formas de abordagem da gestão ambiental. Nada mais natural, portanto, do que o desenho de distintas configurações padronizadas de variáveis, devidamente parametrizadas, para atender às particularidades tipológicas de incubadoras.

Para finalizar, cabe registrar o reconhecimento de que o alcance potencial de incubadoras, diante do universo de micro e pequenas empresas, existentes no Brasil e em todo o planeta, é bastante restrito. Nada impede, no entanto, que essa modalidade organizacional possa ser tratada como espécie de cobaia, para testar e avaliar a aplicabilidade e a operacionalidade de um conjunto de instrumentos de potenciais políticas públicas, capazes de promover estímulos das mais variadas ordens (econômicas, psicológicas, mercadológicas, legais, culturais e outras), indutores da adoção de estratégias, práticas e sistemas de gestão ambiental, pelas empresas abrigadas e assistidas. Paralelamente aos testes, devem ser consideradas, com base nas variáveis do indicador, as potenciais barreiras, do mesmo modo que o conjunto dos custos implícitos à implantação de tais políticas públicas.

\section{Referências}

BARBIERI, J. C. Gestão ambiental empresarial. São Paulo: Saraiva, 2004.

BARBIERI, J. C. O local e o global na implementação do desenvolvimento sustentável. In: CABRAL, A.; COELHO, L. (Orgs.). Mundo em transformação: caminhos para o desenvolvimento sustentável. Belo Horizonte: Autêntica, 2006. p. 23-46.

BRIO, J. A.; JUNQUERA, B. A review of the literature on environmental innovation management in SMEs: implications for public policies. Technovation, v. 23, p. 939-948, 2003.

BUARQUE, S. C. Construindo o desenvolvimento local: metodologia de planejamento. Rio de Janeiro: Garamond, 2004. 
COMISSÃO MUNDIAL SOBRE MEIO AMBIENTE E DESENVOLVIMENTO - CMMAD. Nosso Futuro Comum. Rio de Janeiro: Editora Fundação Getúlio Vargas, 1991.

COMPÊND10 para a sustentabilidade. Movimento da RS na A. Latina. 2008. Disponível em: <http://www.institutoatkwhh. org.br/compendio/?q=node/10>. Acesso em: 19 fev. 2008.

CONSELHO EMPRESARIAL BRASILEIRO PARA 0 DESENVOLVIMENTO SUSTENTÁVEL - CEBDS. Quem somos. Disponivel em: http://www.cebds.org.br/cebds/cebds-quemsomos.asp. Acesso em: 15 fev. 2008.

FEDERAÇÃO E CENTRO DAS INDÚSTRIAS DO ESTADO DE SÃO PAULO - FIESP/CIESP. Responsabilidade social empresarial: panoramas e perspectivas. São Paulo: FIESP/CIESP, 2003.

FONSECA, S. A. Avaliação do processo de implantação e do desempenho de incubadoras empresariais mistas: um estudo de caso no Estado de São Paulo. 2000. 203 f. Tese (Doutorado em Administração) - Faculdade de Economia, Administração e Contabilidade, Universidade de São Paulo, São Paulo, 2000.

GARROD, B.; CHADWICK, P. Environmental management and business strategy: towards a new strategic paradigm. Futures, v. 28, n. 1, p. 37-50, 1996.

GlL, A. C. Como elaborar projetos de pesquisa. São Paulo: Atlas, 1991.

HERAS, 1.; ARANA, G. Alternative models for environmental management in SMEs: the case of Ekoscan vs. ISO 14001. Journal of Cleaner Production, n. 18, p. 726-735, 2010.

JABBOUR, C. J. C. Contribuição da gestão de recursos humanos para a evolução da gestão ambiental empresarial: survey e estudo de múltiplos casos. 2007. 166 f. Tese (Doutorado em Engenharia de Produção) - Escola de Engenharia de São Carlos, Universidade de São Paulo, São Carlos, 2007.

JABBOUR, C. J. C.; FONSECA, S. A. A performance de incubadoras empresariais do interior paulista à luz de um novo modelo de avaliação de desempenho. Produção Online, v. 5, n. 4, 2005.

JEPPESEN, S. Critical realism as an approach to unfolding empirical findings: thoughts on fieldwork in South Africa on SMEs and environment. The Journal of Transdisciplinary Environmental Studies. v. 4, n. 1, p. 1-9, 2005. Spetial lssue.
Disponivel em: <http://www.journaltes.dk/vol\%204\%20 no\%201/no_5_L.pdf>. Acesso em: 28 fev. 2008.

KUEHR, R. Environmental technologies e from misleading interpretations to an operational categorisation \& definition. Journal of Cleaner Production, v. 15, 2007.

MAKOWER, J. Beyond the bottom line: putting social responsibility to work for your business and the world. New York: Simon \& Schuster, 1994.

MERRITT, J. Q. E.m. into SME won't go? Attitudes, awareness and practices in the London borough of Croydon. Business Strategy and Environment, v. 7, p. 90-100, 1998.

MILES, M. P.; MUNILLA, L. S.; MCCLUG, T. The impact of 150 14000 environmental management standards on small and medium sized enterprises. Journal of Quality Management, v. 4, n. 1, p. 111-122, 1999.

NATIONAL BUSINESS INCUBATION ASSOCIATION - NBIA. Inccubator quick facts. 2008. Disponivel em: <http://www. nbia.org.br>. Acesso em: 20 fev. 2008.

NICOLELLA, G.; MARQUES, J. F.; SKORUPA, L. A. Sistema de gestão ambiental: aspectos teóricos e análise de um conjunto de empresas da região de Campinas, SP. Jaguariúna: Embrapa Meio Ambiente, 2004. Disponivel em: <http://www.cnpma. embrapa.br/download/documentos_39.pdf>. Acesso em: 10 out. 2007.

PEREZ-SANCHEZ, D.; BARTON, J. R.; BOWER, D. Implementing environmental management in SMEs. Corporate Social Responsibility and Environmental Management, n. 10, p. 67-77, 2003.

REDMOND, J.; WALKER, E.; WANG, C. Issues for small businesses with waste management. Journal of Environmental Management, n. 88, p. 275-285, 2008.

RUTHERFOORD, R.; BLACKBURN, R. A.; SPENCE, l. J. Environmental management and the small firm - an international comparison. International Journal of Entrepreneurial Behaviour \& Research, v. 6, n. 6, p. 310-326, 2000.

SERVIÇO BRASILEIRO DE APOIO ÀS MICRO E PEQUENAS EMPRESAS - SEBRAE. Onde estão as micro e pequenas empresas no Brasil. São Paulo: SEBRAE, 2006.

YIN, R. K. Case study research: design and methods. Newbury Park: Sage, 1990. 165 p.

\title{
Environmental management: a planet's pledge, a challenge for public policies, incubators and small firms
}

\begin{abstract}
The paper aims to contribute to academic reflections on the role of business incubators as institutional agents to promote environmental performance by small firms. Based on the assumption that these firms have natural structural weaknesses and, as a consequence, intrinsic difficulties in investing in environmental assets, the paper suggests that a particular public policy, namely, business incubators, could contribute to overcoming these barriers and thus pave the way for environmental investments. Two important findings should be highlighted: a) the neglect of the incubators investigated (and thus, of the nurtured firms) with respect to environmental performance; b) the absence of stimuli, from business incubators, for environmental investments. From the results, an important conclusion may be drawn: namely, that where weak patterns of environmental performance are identified, both the incubators and the firms being nurtured, should create and implement an array of measures, consisting mainly of public policies, conducive to changes in behaviors and attitudes.
\end{abstract}

\section{Keywords}

Business incubators. Environmental strategy indicator. Environmental management systems. Performance evaluation of business incubators. 